\title{
Towards Recyclable Nanoporous Polymer Membranes for the Synthesis of One-dimensional Nanoscale Gold Colloids
}

\author{
Nadejda Sertova, ${ }^{1}$ Marcel Toulemonde, ${ }^{2}$ and Torsten Hegmann ${ }^{1,3}$
}

ERRATUM TO: JOURNAL OF INORGANIC

AND ORGANOMETALLIC POLYMERS AND

MATERIALS DOI: 10.1007/s10904-006-9023-1

The submitted and accepted dates for this paper were inadvertently omitted. The dates are as follows:

Submitted October 2, 2005; accepted October 4, 2005

The online version of the original article can be found at http:// dx.doi.org/10.1007/s10904-006-9023-1

${ }^{1}$ Department of Chemistry, University of Manitoba, 144 Dysart Road, Winnipeg, Manitoba, Canada.R3T 2N2,

2 CIRIL, Laboratoire Commun CEA-CNRS-ENSICAEN, Université Caen, Bp 5133, 14070, Caen Cedex 5, France.

${ }^{3}$ To whom correspondence should be addressed.

E-mail: hegmannt@cc.umanitoba.ca 